\title{
Who survives a recession? Specialization against diversification in the digital publishing industry
}

\begin{abstract}
Purpose - This paper studies the empirical relationship between specialization, diversification and rate of survival in the digital publishing industry. The sample includes all publishing companies in Italy that produce electronic content and distribute it through Internet platforms.
\end{abstract}

Design/methodology/approach - The first part of the paper discusses the pros and cons of specialization against diversification, and applies the related economic theories to the digital publishing industry. The empirical work regarding the factors that affect firm survival is reviewed. The second part is empirical and analyzes the diversification strategies of 2838 Italian digital editors between 1995 and 2014, and the impact of diversification on the probability of survival.

Findings - On the whole, digital publishing companies that are also active in traditional print activities has been constantly declining. However, those who combine print and digital activities or operate other mass media businesses have a higher probability of surviving in the market. These findings hold controlling for firm size and market structure, before and after the economic crisis exploded in 2009, in different geographical areas and by different legal forms of publishing companies. Practical implications - The study provides mass media scholars as well as practitioners with detailed information on the digital publishing trends in the medium term. As the industry often presents country-specific characteristics, the econometric analysis should also be integrated with case studies that highlight particular survival conditions.

Keywords. Digital publishing, firm survival, specialization, diversification. 


\section{Introduction}

The first phase in the evolution of digital publishing, beginning in the 1980s, arose from the development of software packages that enabled publications such as magazines to be laid out on computer screens and saved as electronic files. However, at this stage, the resulting files were invariably sent to be printed in hard copy. The second phase started in the mid-1990s and revolved mainly around the Internet. The development of Internet technology and its global diffusion boosted the success of digital contents. The appearance and then proliferation of online newspapers and magazines, e-books and similar products soon convinced the experts that a new era of information was beginning. Today, enabling consumers to read newspapers and magazines via a digital device such as smart phones and tablets, which support the reconfiguration of paper-based products as apps, can be considered as the third and last phase in the evolution of the digital publishing industry. In this paper, the term "digital publishing" refers to the distribution via the Internet of electronic information and entertainment content.

The first experiences of digital publishing were seen as "product innovations", as they were launched by traditional media operators, for example editors of print newspapers, who were challenging unexplored fields. The content of information or entertainment was similar, but the presentation of the product and the modes of distribution and consumption had changed radically. After twenty years, the digital publishing industry is still heterogeneous and publishing companies have not yet established profitable business models. In addition, consumers have attained an active role in the production of information. Thus digital publishing is still "evolving", and at the same time, it can no longer be considered as a form of product or process innovation. It is a mature industry where young entrepreneurs and digital natives enter the market and inaugurate new formats, innovative services and unique contents. They thus choose to specialize in digital publishing or to diversify towards traditional products such as print newspapers, magazines and other formats of the "old" mass media.

Of course, historical and technological factors initially drove the combination of print publishing and digital editorial activities. On the one hand, traditional editors had the 
experience and the appropriate resources to be the pioneers in digital markets. In addition, many of the production factors of print and digital publishing were the same and guaranteed significant economies of scope, thus increasing efficiency in production and distribution. On the other hand, the production and consumption of digital content presented a number of novelties that induced new and inexperienced companies to enter the market. The consumption of digital content was, in terms of form and intensity, a largely unexplored field and required a new process of production and distribution. Nobody knew the preferences of the "digital reader" and many believed that traditional print editors, linked to old schemes, could not interpret the evolution of consumption patterns correctly.

Who has won after twenty years? The statistics display the relentless decline in circulation, revenues and profits of print industries. However, digital publishing does not necessarily ensure profits for the operators, nor, within digital media, have inexperienced and specialized operators necessarily done any better than their elder competitors. Specialization in digital publishing is a key to success when economies of scale and network externalities lead to quasi monopolies, according to the "the winner takes it all" rule (consider, for instance, Wikipedia). At the same time, diversification and firm experience may guarantee a higher probability of survival in a large, fragmented and competitive market (for example, the Wall Street Journal is the second largest newspaper in terms of print circulation and the first in terms of digital subscriptions, as of 2013). These issues can now be examined over several years and in relation to large samples. A medium term analysis can identify the prevalent patterns of specialization in the industry and how different modes of organization struggle for survival during the economic highs and lows.

This paper thus presents an empirical analysis of 2838 digital publishing firms active in Italy between 1995 and 2013, and studies the relationship between specialization, diversification and rate of survival in the market. The paper aims to assess whether those digital companies that are also active in print publishing and other media markets have a greater ability to resist the impact of an economic recession. The economic crisis exploded in Italy in 2009 and eroded the Italian GDP by $11 \%$ in five years (2009-2013). The contraction of the business cycle provides an opportunity 
to examine the reaction of digital publishing companies to an unpredictable event.

One of the paper's key features is the nature of the database used, because each company is associated with one or more activities of the media sector (digital publishing, print publishing, radio and television broadcasting, provision of Internet services, advertising sale). This enables the degree of diversification of media companies to be directly measured.

In addition, the sample includes all entities that were registered as media companies between 1995 and 2013. Of course, a large sample means a high level of heterogeneity of firms. For example, the sample includes large state-controlled multimedia companies as well as sole proprietorship firms specialized in the provision of digital content. However such heterogeneity derives exactly from the specific characteristic of digital markets, which have long been highlighted by the experts: the production and distribution of content do not entail high set up costs and enable small, inexperienced and specialized firms to launch editorial activities.

Finally, the novelty of the paper lies in its central focus on the digital publishing industry. In fact, previous studies on the combination of traditional and digital businesses have concentrated on traditional media companies (print newspapers, magazines, books) and on the strategies developed to cope with the digital revolution. This paper considers the very same issue from the opposite perspective: how digital companies can adapt their strategies to survive in a market where traditional print activities still play a major role.

The empirical analysis produced the following results. The share of digital media companies that are also active in traditional print activities has been constantly declining between 1995 and 2013. This figure would show a "revealed advantage" of specialization in digital publishing. However, digital companies that maintain print activities or that diversify in other media businesses have a higher probability of surviving in the market. Firm size, population density and GDP per capita do not affect the results, while the intensity of competition is positively associated with firm survival. These findings hold before and after the economic crisis exploded in 2009, in different areas of the country and across distinct legal forms of digital publishing companies. 
The paper is organized as follows. The next section briefly reviews the theories of the impact of the integration of economic activities on the success/failure of the market. These theories provide the background for the empirical strategy that is used later on. Section 3 describes the data and presents the summary statistics. Section 4 shows the results of the empirical analysis. The last section presents the conclusions, discussing the limitations of the present research and its possible future directions.

\section{Diversification, specialization and their impact on firm efficiency and firm survival: related literature and previous empirical work}

Mass media companies are involved in multiple combinations of economic activities, through diversification, differentiation and vertical integration. At the same time, many companies choose to run a single business. This section reviews the theoretical pros and cons of combining economic activities against the benefits of specialization. In addition, this section highlights the most important results of the economics of firm survival, which is the variable of interest in the following sections. To our knowledge, no empirical study has explicitly examined the relationship between specialization/diversification and firm survival in the publishing industry. This issue is also relatively unexplored in other sectors. Therefore, the key issues are presented in general terms and adapted to the digital publishing industry.

A firm has the incentive to conduct more than one economic activity in order to attain economies of scope (Teece, 1982; Penrose, 1995) generated by distributing various fixed costs on a mix of products or intermediate inputs, given a certain degree of cost complementarity. In addition, the concentration of separate activities within the same organization reduces risks connected to the exchange of inputs, goods and services. This applies to both diversification and vertical integration, especially if the provision of inputs is subject to uncertainty (Carlton, 1979).

There are natural economies of scope between print and digital publishing. The creation of the primary product, that is, information or entertainment content, requires the same production factors in both print and digital publishing. In terms of newspapers and magazines, the gathering of stories, events and opinions generates a raw material that can be developed and organized for both print and digital outlets. In 
addition, the updates and freshness, typical of online information and entertainment, can be re-worked in print editions, while the in-depth analysis of print editions can be brought forward in time or parcelled out in consecutive editions of online versions. Economies of scope are less evident in book publishing, because digital versions look like identical reproductions of print editions, and vice versa. When physical and digital products look the same, substitution seems to prevail upon complementarities especially in terms of consumption patterns. If this is the case, offering both print and digital products could lead to cannibalization. However, Øiestad and Bugge (2014) argue that print and digital technologies can be developed in parallel in some contexts, and that the new technologies do not necessarily "disrupt" the old ones, but rather involve new business models ${ }^{1}$. Picard (2003) also believes that editorial activities can increase their audience and revenues through diversification in both print and digital products. This optimism is contrasted by Latzer (2009), who found no concrete result regarding the relationship between editorial diversification and firm profitability, and Kung (2007), who argues that conducting old and new business together may be complicated and unprofitable ${ }^{2}$.

Broadly speaking, some media product families share key elements: the medium is a platform, where the design, components and other assets are common for a set of products. Economies of scope occur because platforms make it cheaper to tailor products to consumer segments and diversification results from building and extending platform capabilities. The combination of paper and digital products, however, has not always proven successful. There is no evidence that a diversification strategy naturally leads to higher revenues and profits ${ }^{3}$, although media firms are ready to investigate unexplored product strategies ${ }^{4}$.

1 According to Christensen (2013), disruptive technologies, such as digital publishing, do not offer incremental improvements but change the game completely. Christensen (2013) argues that this occurrence determines an "innovation dilemma".

2 At a more general level, Porter (1996) argues that managing new and old technologies together may lead to the degradation of the core business.

3 Prior research suggests that in many industries, diversification is correlated with poorer performance (Montgomery, 1985; Montgomery and Wernerfelt, 1988; Montgomery, 1994). 4 In the case of Norwegian newspapers, Bugge and Øiestad (2014) suggest that media firms are prone to explore a dynamic interplay between specialization and diversification, however the available information does not facilitate an easy evaluation of the profitability of such 
While economies of scope can provide the motivation for combining print and digital editorial activities, economies of scale may exert a conflicting force and push firms to specialize in one of the two. In fact, if a firm carries out more than one business, it may have difficulty in reaching the minimum efficient scale in each one. Economies of scale are a crucial feature of all media products: due to the "first copy" effect, the high fixed costs in the production of the original content are associated with low marginal costs for reproduction and distribution. In digital content, the marginal cost of distribution is close to zero and economies of scale are thus amplified. These facts may lead a firm to concentrate on a single business in order to maximize efficiency. Thus, some argue that digital products have an advantage over paper products. For example, Doyle (2002) argues that "the benefits of digital technology are greatly magnified because of the coexistence, for media content, of both economies of scale and of scope" (page 145). This cannot be easily demonstrated, however digital products definitely appear to be more adjustable, in relative terms, to different segments of consumers. At the same time, if many consumers are still anchored to paper and print products, specializing in digital products could cannibalize the traditional products of the same firm (Gallaugher et al., 2001; Schulze et al., 2004; Simon and Kadiyali, 2007; Hu and Smith, 2013).

Broadly speaking, the relationship between the old and new business, that is, paper and digital media content, and firm efficiency is unclear, industry-specific and hugely dependent on the industry's characteristics. The combination of economies of scale and economies of scope can be fruitful but also unconstructive.

Other considerations complicate the picture. First, almost all studies on the benefits and disadvantages of specialization/diversification in media industries assume the perspective of large established firms, thus excluding any predictions regarding the majority of small/medium firms active in the market. Second, and as a consequence, the specialization/diversification dilemma seems to involve only traditional editors. In other words, the objective of most papers is to clarify the pros and cons of moving from a traditional paper industry to a "new" environment, where paper and digital greater intensity and complexity of actions, for example through diversification, have a higher probability of surviving, however the results are highly variable across industries. 
products can coexist and be offered to new consumers and digital natives. Finally, some theories developed in the field of Industrial Organization emphasize that the organizational choices reflect the heterogeneity of firms, in terms of their ability to develop sticky, local and specific competencies, and for a given technological variety across sectors (see Bresnahan and Levin, 2012, for a review). As a consequence, there are firms with different degrees of integration within the same sector (Langlois and Robertson, 1995), and the prediction of a stable relationship between firm strategies and profitability is not easy.

In conclusion, the theoretical and empirical literature on specialization against diversification does not suggest concrete results for market success or a greater ability to survive within an industry. In addition, digital publishing industries have never been the direct object of analysis.

On the other hand, the empirical literature on firm survival has explored in detail the impact of firm and industry characteristics on the probability of exiting the market. The most common explanatory variables are firm size, firm age, regional economic prosperity, intensity of competition, availability of resources (broadly speaking, environmental characteristics) and legal form. Due to their importance in previous studies, these variables will be considered in the empirical analysis.

The major empirical results of the economics of firm survival can be summarized as follows. Regarding firm size, the empirical studies have generally found that larger firms have a higher probability of survival (Aldrich and Auster, 1986; Mata and Portugal, 1994; Wagner, 1994; Geroski et al., 2002; Esteve-Perez and MañezCastillejo, 2004; Strotmann, 2007). The disadvantage of smaller firms is attributable to operations below the minimum efficient scale, financial constraints, the difficulty in recruiting specialized skills, scarce economies of scope, lower risk diversification and harsh competition from larger and experienced competitors. However, some studies suggest that the liability of smallness is less pronounced in high-technology industries (Audretsch, 1995; Mata et al., 1995; Raz and Gloor, 2007). ${ }^{5}$

\footnotetext{
${ }^{5}$ Another result is the liability of newness: controlling for firm size, the first years of operation present a higher risk of failure/exit (Mata and Portugal, 1994). A firm's experience in the market (to build business relations with suppliers, convince consumers to try new products and so on) is approximated with firm age and increases the probability of survival.
} 
The prosperity of the region where a firm is located may have a positive influence on its economic success and probability of survival (Audretsch, 1995; Boeri and Bellmann, 1995), although industry trends can affect this relationship. When an industry is at an early stage of the product cycle, the lack of standardized processes makes market entry particularly risky (Audretsch, 1995). Another regional factor emphasized in previous studies is the intensity of competition. When the number of firms in an industry is high relative to market demand, the chance of survival is lower (Hannan and Carroll, 1992). At the same time, the regional agglomeration of economic activities can generate external economies of scale, which compensate for the higher competition of those companies with a similar location (Audretsch and Feldman, 1996; Porter, 1998). Knowledge spillovers associated with spatial proximity can help firms survive in the market (Krugman, 1991), even with multiple and aggressive competitors. Other local factors may affect the rate of survival, for example the availability of human resources and qualified labor. Some studies also suggest that regional population density and agglomeration are linked to innovation and success in the market (Fritsch et al., 2006). Finally, some scholars have analyzed the impact of different legal forms on the probability of survival. Limited liability companies present a lower probability of exiting the market, although this cannot be generalized (Mata and Portugal, 2002; Esteve-Perez and Mañez-Castillejo, 2004; Esteve-Perez and Manez-Castrillejo, 2008). The empirical analysis of Sections 3 and 4 will take into account these factors, although it is mostly focused on the impact of diversification on the probability of firm survival.

\section{Data and summary statistics}

The Italian independent authority for telecommunications and mass media industries (hereafter, AGCOM), is the main data source. The tasks assigned to AGCOM are to

Unfortunately, the database of this paper does not provide a reliable estimation of when each company was set up. Hence, firm age is not included among the explanatory or control variables. 
"ensure equitable conditions for fair market competition and to protect the fundamental rights of all citizens". AGCOM was established by Italian law in 1997 along with the Register of Communications Operators (ROC), a listing of companies in the communications industry. The purpose of the ROC, which is outlined on the AGCOM website (www.agcom.it), is to ensure transparency and public knowledge of the ownership structures, to permit the application of anti-concentration rules and defend the pluralism of information. The following companies must appear in the ROC: network operators, such as Internet providers; radio and television broadcasters; advertising sale agencies; producers of audio and video content; press agencies, editors of newspapers, magazines and journals; electronic publishers; and providers of electronic communication services, including telephone companies. During registration, each company declares whether it is involved in one or more of these activities.

This paper considers digital publishing companies as the unit of analysis. Hence, in what follows, the variable print is equal to 1 if a digital publishing company is also active in paper publishing, otherwise it is equal to 0 otherwise. The variable diversification is equal to 1 if a firm is active in other media businesses besides print or digital publishing, otherwise to 0 .

The ROC includes the registration date and possible cancellations, which in this paper are interpreted as a proxy of market exit. The ROC data are then combined with the AIDA database, which includes economic and financial information; this paper specifically considers the number of employees as a proxy of firm size. The variable GDPpc (Gross Domestic Product per capita) describes the regional prosperity where a firm is located. Competition measures the number of the other media firms operating in the same province ${ }^{6}$. GDPpc and (population) density variables are also built at a province level using the online ISTAT database.

We consider the variables size, GDPpc, density and competition in the year in which a firm enrols itself in the ROC. The variable SC ("società di capitali") is equal to 1 (otherwise to 0 ) in the case of "commercial companies", that is, all companies

\footnotetext{
${ }^{6}$ In Italy, there are 110 provinces. A province is an administrative division of intermediate level between a municipality (comune) and a region (regione).
} 
excluding sole proprietorships, cooperatives, non-profit associations, statutory corporations, and foundations (Table 1).

The whole sample consists of 2838 companies, registered between January 1995 and December 2013, 479 of which have been cancelled from the ROC. Most digital publishing firms are "commercial companies", although many (46\%) are sole proprietorships, cooperatives or non-profit associations. More than a half combine print and digital publishing (48.43\% in the case of cancelled firms), while, on the whole, few companies diversify their activities in advertising, television, radio or telecommunications. On average, cancelled companies are slightly smaller than active ones, operate in provinces with a lower density of population and compete with more media firms within their province. On the other hand, there is no great difference between active and cancelled companies in terms of regional economic prosperity. Finally, the distribution of active and cancelled companies across northern, central and southern Italy is similar.

Table 1

Figure 1 shows the new registrations and cancellations between 1995 and 2013. The registrations present a peak during the dot-com bubble, a steady increase in the subsequent years and a significant decline after 2011. As in many other industries, the financial and economic crisis had a significant impact approximately two years after its actual "explosion" at the end of 2008. On the other hand, cancellations show a considerable increase after 2009 with a peak in 2010.

Figure 1

Figure 2 shows the digital publishing companies also operating in print publishing between 1995 and 2013 (upper time series). The share of companies that combine traditional and digital publishing shows a constant decline, from nearly 90\% in 1995 to less than 60\% in December 2013. Apparently, the financial crisis did not affect this trend, which thus reveals the preference for specialization in digital activities. In contrast, the share of digital editors that diversify in advertising, telecommunications, 
radio or television remains around $10 \%$ in the period under review (lower time series).

Figure 2

To introduce the statistical analysis of the next section, Table 2 reports a probit regression where the dependent variable, survival, is 1 for active firms and otherwise

0 . Table 2 completely ignores the chronological dimension of firm survival. Columns III and IV shows the same regression before and after 1 January 2009.

Table 2

On the whole, the digital companies involved in print publishing or that diversify their business have a higher probability of staying in the market, while the effect of firm size is significant but very small. The intensity of competition is associated with a higher probability of survival, while the effect of regional prosperity is ambiguous. Digital companies that are active in richer provinces have an overall lower probability of surviving, however this effect disappears if the sample is split in two, before and after 1 January 2009. Population density and legal form do not have any impact on the probability of exiting the industry. The significance of the models reported in Table 2 is in any case rather small.

\section{Print publishing, diversification and firm survival: duration analysis}

To analyze whether the likelihood of survival is invariant to print publishing and diversification of digital companies, this paper uses the analysis of duration. The variable of interest is the length of time that elapses from the beginning of an event either until its end or the end of the analysis. Thus, the observation consists of a cross section of durations $t_{1}, t_{2}, \ldots, t_{\mathrm{n}} \in T$, where $T$ is a discrete or continuous random variable. The analysis of duration estimates the probability that the event "failure" will occur in the next period. In this paper, the dependent variable is the span of survival of digital publishing firms, calculated as the difference between time $t$ and the firm's registration in the ROC, while the failure event coincides with the cancellation from the ROC. Therefore, the variable $T$ is by necessity censored. 
To assess the impact of the regressors, that is, print publishing and diversification, on the probability of survival, the Cox Proportional Hazard Regression estimates the hazard function $h_{i}(t)$ of a firm $i$ is

$$
h_{i}(t)=h\left(t, x_{i}\right)=h_{0}(t) \exp \left(x_{i}^{\prime} \beta\right)
$$

where $h_{0}(t)$ is an arbitrary and unspecified baseline hazard function, $x_{i}$ is a vector of measured explanatory variables of the $i$-th firm, and $\beta$ is the vector of unknown parameters to be estimated. A negative sign of the coefficient or a hazard ratio lower than one means that the hazard rate decreases, that is, the corresponding variable is associated with a higher probability of survival.

Figures 3 and 4 show the Kaplan-Meier product-limit estimate of the survivor function. The graphs compare specialized against print digital companies (Figure 3), and specialized against diversified digital companies (Figure 4). This comparison is descriptive since the condition of all other things being equal is not satisfied. Figure 3 shows that companies specialized in digital publishing exhibit a survival function that decreases more rapidly. This trend is amplified in the last few years of observation, corresponding to the stagnation of the national economy. The same can be said for digital companies that do not diversify in other media businesses (Figure 4), although the difference between the survival functions is less pronounced.

Figure 3

Figure 4

Although highly informative, these statistics must be combined with the control variables discussed in the previous section, which can affect the relationship between the extent of economic integration of digital companies and the probability of surviving in the market. To explore this theme, Table 4 shows the results of a Cox 
regression for the entire sample (Column II) and for the period before and after the first of January 2009 (Columns III and IV) ${ }^{7}$.

\section{Table 3}

As anticipated in the summary statistics, the digital publishing companies that also produce print editions or that diversify in other mass media sectors have a lower probability of exiting the market, although during the economic crisis the benefits of diversification are less pronounced. The hazard ratios of firm size are very close to one: the effect of dimension on the probability of survival is negligible though the hazard ratios are always significant. Hazard ratios of competition are small and significant: the agglomeration of media and telecommunications businesses exerts a positive effect on the probability of survival. Hence, the advantages of the regional concentration of companies and external economies of scale more than compensate for the disadvantages of the intense rivalry of many competitors.

Finally, the economic prosperity at a province level, the legal form of the companies under review and population density have no influence on the probability of surviving. The empirical findings are notable: controlling for other firm characteristics and market structure, the digital companies that operate in "traditional" media business have a stable higher probability of surviving in the market, because the results are essentially the same, both before and during the crisis.

To control the robustness of the results, the sample was divided into companies located in northern, central and southern Italy, and the Cox regressions were run separately. In addition, the analysis was replicated for only commercial companies, thus excluding sole proprietorship and all non-profit association categories. The additional regressions confirmed the results presented in this section.

\footnotetext{
${ }^{7}$ The Cox regression model assumes that the hazard ratio is proportional over time. A Schoenfeld test shows that there is no evidence that the proportional hazards assumption is violated for each covariate.
} 
Figure 5 shows the (smoothed) hazard function of specialized digital against print and digital publishing companies. The hazard functions follow the general economic trend. The hazard increases between the end of the old century and the beginning of the new one, when the explosion of the dotcom bubble drove many digital companies out of the market. After a considerable decline in the risk of "failure", the companies specialized in digital publishing faced an increase in the hazard rate between 2008 and 2009. On the other hand, those companies that also operate in print publishing have an opposite trend, at least until 2011-2012.

\section{Conclusions}

The economic literature regarding the tension between digital and print activities within the publishing industry usually assumes the traditional print system as the unit of analysis. The main research question concerns the attitude and response of traditional media companies to the technological shock of digitization (Boczkowski, 2005; Allan, 2006; Mitchelstein and Boczkowski, 2009; Øiestad and Bugge, 2014). Several studies have attempted to answer the following questions: How should companies deal with the technological evolution and what is the optimal rate of innovation? How should companies react to the changing habits of users and consumers? Should the old technologies of production and distribution be abandoned or maintained?

This paper adopted a different perspective and analyzed the digital publishing industry as an established and autonomous sector. This is because today many entrepreneurs launch digital products in mass media markets, with no concern as to who the "old" media were or what they did in the past. Also the consumers are different. Many digital natives have little experience with paper products, while others will never purchase information or entertainment content on a traditional physical support. In other words, the question is reversed: should digital companies specialize in their core business or maintain strong relationships with print products and "traditional" readers? 
This paper has contributed to the debate by looking at what the Italian digital publishing companies actually "were" between 1995 and 2013. The empirical analysis focused on a survival analysis and yielded the following results. Controlling for firm size and other structural characteristics of companies and markets, those digital publishing companies that were also involved in paper publishing or in other mass media businesses have a higher probability of surviving in the market. This result holds both before and after the economic crisis that exploded in 2009, in different areas of the country, and for distinct legal forms of digital publishing companies. These findings are interesting in two respects. The first message regards the specialization/diversification dilemma. Most analyses of digital production processes emphasize the large economies of scale due to the variable costs close to zero both in production and distribution. In addition, network effects on the users' side require a critical mass of consumers to break even. These features of digital publishing markets may induce some firms to specialize in a single product or process and increase the scale of production. However, the data reveal that specializing in digital publishing reduces the probability of continuing operations as a publisher. The combination of economic operations in the publishing industry is a powerful instrument for survival in a competitive environment. The benefits of diversification, which some scholars have highlighted in large and multimedia firms (Chan-Olmsted and Chang, 2003;

Vukanovic, 2009; Doyle, 2014), accrue also to small entities ${ }^{8}$.

The second message regards the relationship between the summary statistics and the regression findings. Figure 2 shows that increasing numbers of companies enter the industry as pure digital publishers. Certainly, digital technologies provide opportunities for small and inexperienced firms. The low set-up costs involved convince many entrepreneurs to create digital content and explore new business models. However, they are not successful in the short-medium run, as demonstrated by the analysis of duration. This apparent contradiction is striking, because the greater ability to survive of the print and diversified digital companies was confirmed during the worst economic crisis since the Great Depression. The share of pure digital

\footnotetext{
${ }^{8}$ Further reflections on the positive combination of digitization and diversification in the publishing industries can be found in Carreiro (2010) and Flew (2011).
} 
editors has been increasing for nearly twenty years. At the same time, they fail more frequently than their diversified competitors. Why? The development of a theoretical model capable of explaining such a phenomenon is beyond the scope of the paper ${ }^{9}$. However, this issue merits an in-depth analysis in the next future.

The analysis presented in this paper has important limitations. First, the empirical analysis concentrated on the analysis of survival, because surviving in the market is the necessary condition to obtain revenues, market share and profits. However, staying in the market does not necessarily ensure economic success. Similarly, cancellations from the dataset do not necessarily mean that the companies failed or exited the market. Some companies might have changed name, while others might have been transformed by a merger or acquisition (Chan-Olmsted, 1998; Chon et al., 2003).

Second, digital publishing companies that are active in print and other operations, could be established media companies, who were active well before 1995, with great experience and the opportunity to exploit both scale and scope economies. This would thus explain their greater ability to survive during the economic highs and lows (Bigelow and Argyres, 2008). We believe, however, that controlling for firm size can reduce, at least partially, this kind of bias. In reality, firm's experience even in a close technology or industry does not ensure success in the market. Before 1995 there were no digital publishing companies (as defined in the Introduction) and all media firms were confronted by new technological paradigms of production and consumption. Many established media firms did incorporate digital activities and benefited from several complementarities between resources and assets employed both in print and digital editions. That said, the digital revolution completely changed the competitive arena, and also large and experienced media conglomerates experienced several difficulties in adaptation. In other words, a firm's experience can explain a piece of the story, but not everything.

\footnotetext{
${ }^{9}$ In relation to the German publishing industry, Hass (2011) puts forward a theoretical model in which new and successful entrepreneurial activities are organized within established media companies.
} 
A final limitation of the paper derives from the size of the sample and its resulting heterogeneity. Many companies are non-profit associations, others are probably simple marketing divisions of firms that produce goods or services in rather distinct economic sectors. Including all Italian firms registered as digital publishing companies in the sample is probably excessive. However, from a technical perspective, there is no way of knowing whether the core business of a company is publishing or something else. To a broader extent, mass media, per se, is a "special" economic industry, because it includes distant technologies that are offered to heterogeneous consumers. Mass media show a variety of business models: free and online advertising-based news aggregators compete with subscription-based print newspapers. In addition, identifying the business model does not necessarily clarify the precise mission of publishing companies. For example, many editorial directors would not include profit maximization among the (official) company objectives. In relation to market structure, economic scholars have described the digital revolution as an event enabling small, inexperienced and ground-breaking companies to enter the market and gain popularity with information and entertainment. Thus, the firm and industry boundaries are not clearly defined, and excluding some digital publishing companies from the sample and maintaining others would be rather arbitrary (Thompson, 2013).

The limitations of this paper open the way for further analysis of digital publishing industries. Digital and online publishing has effectively arisen since the mid-1990s. Many media companies, possibly diversified in other media business, quickly responded to the challenge of new technologies and reorganized themselves to compete in the new digital environment. The relationship between firm experience, firm survival and firm performance in the long run must thus be the focus of future empirical studies.

From a methodological perspective, large samples are now available and allow for a generalization of results. However, they do not clarify why a specific organization of economic activities prevails over others. An in depth analysis focusing on specific companies that struggle to stay in the market by adopting different strategies could reveal the structural and behavioural antecedents of survival advantages. Thus, case 
studies can provide support and fruitful integration to the standard econometric analysis of publishing industries. 


\section{References}

Aldrich, H. and Auster, E.R. (1986), "Even Dwarfs Started Small: Liabilities of Age and Size and Their Strategic Implications," Research in Organizational Behavior, Vol. 8 No. 1, pp. 165-186.

Allan, S. (2006), Online News: Journalism and the Internet, Open University Press, Maidenhead.

Audretsch, D. B. and Feldman, M.P. (1996), "Innovative Clusters and the Industry Life Cycle", Review of Industrial Organization, Vol. 11 No. 2, pp.253-273.

Audretsch, D.B. (1995), Innovation and Industry evolution, Mit Press, Cambrisge (MA).

Bigelow, L.S. and Argyres, N. (2008), "Transaction Costs, Industry Experience and Make-or-Buy Decisions in the Population of Early US Auto Firms", Journal of Economic Behavior and Organization, Vol. 66 No. 3, pp. 791-807.

Boczkowski, P.J. (2005), Digitizing the News: Innovation in Online Newspapers, MIT Press, Cambridge (MA).

Boeri, T. and Bellmann, L. (1995), "Post-entry Behavior and the Cycle: Evidence from Germany", International Journal of Industrial Organization, Vol. 13 No. 4, pp. 483500.

Bresnahan, T.F. and Levin, J.D. (2012), "Vertical Integration and Market Structure." (No. w17889). National Bureau of Economic Research.

Brynjolfsson, E., Hu, Y. and Simester, D. (2011), “Goodbye Pareto Principle, Hello Long Tail: The Effect of Search Costs on the Concentration of Product Sales", Management Science, Vol. 57 No. 8, pp. 1373-1386.

Bugge, M.M. and Øiestad, S. (2014), "The Micro-foundations of Regional Branchingthe Case of Digitization of Publishing", European Planning Studies (ahead-of-print),: pp. 1-21.

Carlton, D.W. (1979), "Vertical Integration in Competitive Markets under Uncertainty", Journal of Industrial Economics, Vol. 27 No. 3, pp. 189-209.

Carreiro, E. (2010). Electronic books: how digital devices and supplementary new technologies are changing the face of the publishing industry. Publishing research quarterly, 26(4), 219-235. 
Chandler, A.D. Jr. (1990), Scale and Scope: the Dynamics of Industrial Capitalism, The Belknap Press, Cambridge (MA).

Chan-Olmsted, S.M. (1998), "Mergers, Acquisitions and Convergence: The Strategic Alliances of Broadcasting, Cable Television and Telephone Services", Journal of Media Economics, Vol. 11 No. 3, pp. 33-46.

Chan-Olmsted, S.M. and Chang, B.H. (2003), "Diversification Strategy of Global Media Conglomerates: Examining its Patterns and Determinants", Journal of Media Economics, Vol. 16 No. 4, pp. 213-233.

Chon, B.S., Choi, J.H., Barnett, G.A., Danowski, J.A. and Joo, S.H. (2003), “A Structural Analysis of Media Convergence: Cross-industry Mergers and Acquisitions in the Information Industries", Journal of Media Economics, Vol. 16 No 3, pp. 141-157.

Christensen, C. (2013), The Innovator's Dilemma: When New Technologies Cause Great Firms to Fail, Harvard Business Review Press, Boston (MA).

Doyle, G. (2002), Media Ownership: The Economics and Politics of Convergence and Concentration in the UK and European Media, Sage, London.

Doyle, G. (2014), "Re-invention and Survival: Newspapers in the Era of Digital Multiplatform Delivery", Journal of Media Business Studies, Vol. 10 No. 4, pp. 1-20.

Esteve-Pérez, S. and Mañez-Castillejo, J.A. (2008), "The Resource-based Theory of the Firm and Firm Survival", Small Business Economics, Vol. 30 No. 3, pp. 231-249.

Ferrier, W.J., Smith, K.G. and Grimm, C.M. (1999), "The Role of Competitive Action in Market Share Erosion and Industry Dethronement: A Study of Industry Leaders and Challengers", Academy of Management Journal, Vol. 42 No. 4, pp. 372-388.

Flew, T. (2011). Conglomeration and globalization as accumulation strategies in an age of digital media. The Political Economies of Media: The Transformation of the Global Media Industries, 84.

Fritsch, M., Brixy, U. and Falck, O. (2006), "The Effect of Industry, Region, and Time on New Business Survival-a Multi-dimensional Analysis", Review of Industrial Organization, Vol. 28 No. 3, pp. 285-306.

Gallaugher, J.M., Auger, P. and BarNir, A. (2001), "Revenue Streams and Digital Content Providers: An Empirical Investigation", Information \& Management, Vol. 38 No. 7, pp. 473-485. 
Geroski, P.A., Mata J. and Portugal, P. (2002), "Founding Conditions and the Survival of New Firms", Working paper 1-03, Banco de Portugal, Economic Research Department, Lisbon.

Hannan, M.T. and Carroll, G. (1992), Dynamics of Organizational Populations: Density, Legitimation, and Competition, Oxford University Press, New York.

Hass, B. H. (2011). Intrapreneurship and corporate venturing in the media business: A theoretical framework and examples from the German publishing industry. Journal of Media Business Studies, 8(1), 47-68.

Hu, Y.J. and Smith, M.D. (2013), "The Impact of e-Book Distribution on Print Sales: Analysis of a Natural Experiment." Available at SSRN 1966115.

Krugman, P.R. (1991), Geography and Trade, MIT press, Cambridge (MA).

Küng, L. (2007), “Does Media Management Matter? Establishing the Scope, Rationale and Future Research Agenda for the Discipline", Journal of Media Business Studies, Vol. 4 No. 1, pp. 21-39.

Langlois, R.N. (1988), "Economic Change and the Boundaries of the Firm", Journal of Institutional and Theoretical Economics, Vol. 144 No. 4, pp. 635-657.

Langlois, R.N. and Robertson, P.L. (1995), “Innovation, Networks, and Vertical Integration", Research Policy, Vol. 24 No. 4, pp. 543-562.

Latzer, M. (2009), "Information and Communication Technology Innovations: Radical and Disruptive?" New Media \& Society, Vol. 11 No. 4, pp. 599-619.

Mata, J. and Portugal, P. (1994), "Life Duration of New Firms", Journal of Industrial Economics, Vol. 42 No. 3, pp. 227-245.

Mata, J. and Portugal, P. (2002), "The Survival of New Domestic and Foreign Owned Firms", Strategic Management Journal, Vol. 23 No. 4, pp. 323-343.

Mata, J., Portugal, P. and Guimaraes, P. (1995), "The Survival of New Plants: Start-up Conditions and Post-entry Evolution", International Journal of Industrial Organization, Vol. 13 No. 4, pp. 459-481.

Mitchelstein, E. and Boczkowski, P.J. (2009), "Between Tradition and Change: A Review of Recent Research on Online News Production", Journalism, Vol. 10 No. 5, pp. 562-586. 
Montgomery, C.A. (1985), "Product-market Diversification and Market power", Academy of Management Journal, Vol. 28 No. 4, pp. 789-798.

Montgomery, C.A. (1994), “Corporate Diversification”, Journal of Economic Perspectives, Vol. 8 No. 3, pp. 163-178.

Montgomery, C.A. and Wernerfelt, B. (1988), "Tobin's q and the Importance of Focus in Firm Performance", American Economic Review, Vol. 78 No. 1, pp. 246-250.

$\varnothing$ iestad, S. and Bugge, M.M. (2014), “Digitization of Publishing: Exploration Based on Existing Business Models", Technological Forecasting and Social Change, Vol. 83 No 1, pp. 54-65.

Penrose, E.T. (1995), The Theory of the Growth of the Firm [Electronic book], Oxford University Press, Oxford.

Picard, R.G. (2003), “Cash Cows or Entrecote: Publishing Companies and Disruptive Technologies", Trends in Communication, Vol. 11 No. 2, pp. 127-136.

Porter, M.E. (1998), “Clusters and the New Economics of Competition”, Harvard Business Review, Vol. 76 No. 6, pp. 77-90.

Raz, O. and Gloor, P.A. (2007), "Size Really Matters - New Insights for Start-ups' Survival", Management Science, Vol. 53 No. 2, pp. 169-177.

Schulze, B., Hess, T. and Eggers, B. (2004), "The Internet's Impact on Content Utilization Chains: An Exploratory Case Study on Leading Publishers in Germany", International Journal on Media Management, Vol. 6 No. 1-2, pp. 12-22.

Simon, D.H. and Kadiyali, V. (2007), "The Effect of a Magazine's Free Digital Content on its Print Circulation: Cannibalization or Complementarity?, Information Economics and Policy, Vol. 19 No. 3, pp. 344-361.

Strotmann, H. (2007), "Entrepreneurial Survival”, Small Business Economics, Vol. 28 No. 1, pp. 87-104.

Teece, D.J. (1982), "Towards an Economic Theory of the Multiproduct Firm", Journal of Economic Behavior and Organization, Vol. 3 No. 1, pp. 39-63.

Thompson, J. B. (2013). Merchants of culture: the publishing business in the twentyfirst century. John Wiley \& Sons. 
Vukanovic, Z. (2009). Global paradigm shift: Strategic management of new and digital media in new and digital economics. The International Journal on Media Management, 11(2), 81-90.

Wagner, J. (1994), "The Post-entry Performance of New Small Firms in German

Manufacturing Industries", Journal of Industrial Economics, Vol. 42 No. 2, pp. 141154. 
Table 1. Digital publishing firms in Italy, January 1995- December 2013

\begin{tabular}{lrrr}
\hline \multicolumn{1}{l}{ ACTIVE } & \multicolumn{1}{l}{ CANCELLED } & \multicolumn{1}{l}{ TOTAL } \\
$\mathrm{N}$ & $2359(83.12 \%)$ & $479(16.88 \%)$ & $2838(100 \%)$ \\
$\mathrm{SC}$ & $1323(56.08 \%)$ & $257(53.65 \%)$ & $1580(55.67 \%)$ \\
PRINT & $1360(57.65 \%)$ & $232(48.43 \%)$ & $1592(56.10 \%)$ \\
DIVERSIFICATION & $207(8.77 \%)$ & $31(6.47 \%)$ & $238(8.39 \%)$ \\
SIZE (mean) & 7.92 & 7.31 & 13.22 \\
GDPpc (mean) & 29.85 & 29.33 & 0.029 \\
DENSITY (mean) & 715.27 & 658.85 & 705.75 \\
COMPETITION (mean) & 10.27 & 10.92 & 10.38 \\
NORTH & $819(80.45 \%)$ & $199(19.55 \%)$ & $1018(35.87 \%)$ \\
CENTER & $909(84.95 \%)$ & $161(15.05 \%)$ & $1070(37.70 \%)$ \\
SOUTH & $631(84.13 \%)$ & $119(15.87 \%)$ & $750(26.43 \%)$ \\
\hline NOteS. SZE & in terms & of & \\
\hline
\end{tabular}

Notes. SIZE in terms of employees. DENSITY: inhabitants per $\mathrm{km}^{2}$ in the province where the company is located. GDPpc: GDP per capita at the province level in thousands of euros. COMPETITION: ROC registered firms per 1000 inhabitants at the province level. 
Table 2. Firm characteristics, market structure and probability of survival

\begin{tabular}{llll}
\hline & POOLED SAMPLE & $1995-2008$ & $2009-2013$ \\
\hline PRINT & $0.248^{* * *}$ & $0.320^{* * *}$ & $0.347^{* * *}$ \\
& $(0.057)$ & $(0.079)$ & $(0.091)$ \\
DIVERSIFICATION & $0.256^{* *}$ & $0.270^{* *}$ & $0.446^{*}$ \\
& $(0.109)$ & $(0.130)$ & $(0.231)$ \\
SIZE & $-0.008^{* * *}$ & $0.009^{* *}$ & $-0.082^{* * *}$ \\
& $(0.002)$ & $(0.003)$ & $(0.012)$ \\
GDPpC & $-11.615^{* *}$ & -8.678 & -12.243 \\
& $(4.911)$ & $(7.087)$ & $(7.612)$ \\
COMPETITION & $735.534^{* * *}$ & $645.800^{* * *}$ & $992.572^{* * *}$ \\
& $(159.701)$ & $(211.000)$ & $(269.069)$ \\
DENSITY & $-2.5 \mathrm{E}-05$ & $-4.4 \mathrm{E}-05$ & $3.1 \mathrm{E}-05$ \\
& $(3.8 \mathrm{E}-05)$ & $(5.0 \mathrm{E}-05)$ & $(6.4 \mathrm{E}-05)$ \\
SC & 0.050 & 0.165 & 0.140 \\
& $(0.058)$ & $(0.079)$ & $(0.093)$ \\
Constant & $0.969 * * *$ & $0.334^{*}$ & $1.584^{* * *}$ \\
& $(0.120)$ & $(0.188)$ & $(0.198)$ \\
LL & -1258.635 & -702.44 & -484.361 \\
Pseudo R2 & 0.023 & 0.027 & 0.081 \\
\hline Obs. & 2838 & 1327 & 1511 \\
\hline
\end{tabular}

Notes. Reported values are marginal effects of a probit analysis. Standard errors in parenthesis. PRINT and DIVERSIFICATION are dummies. ${ }^{* * *}$ Significant at the 0.01 level. **Significant at the 0.05 level. *Significant at the 0.10 level. 
Table 3. Cox regression: firm characteristics, market structure and probability of survival

\begin{tabular}{llll}
\hline & POOLED SAMPLE & $1995-2008$ & $2009-2013$ \\
\hline PRINT & $0.558^{* * *}$ & $0.569^{* * *}$ & $0.552^{* * *}$ \\
DIVERSIFICATION & $(0.052)$ & $(0.066)$ & $(0.089)$ \\
& $0.562^{* * *}$ & $0.590^{* *}$ & $0.441^{*}$ \\
SIZE & $(0.106)$ & $(0.124)$ & $(0.201)$ \\
& $0.923^{* * *}$ & $0.932^{* * *}$ & $0.946^{*}$ \\
GDPpC & $(0.009)$ & $(0.011)$ & $(0.027)$ \\
& 1.011 & 1.006 & $1.024^{*}$ \\
COMPETITION & $(0.008)$ & $(0.010)$ & $(0.013)$ \\
& $0.287^{* * *}$ & $0.371^{* * *}$ & $0.150^{* * *}$ \\
DENSITY & $(0.077)$ & $(0.119)$ & $(0.074)$ \\
& 1.000 & 1.000 & 0.999 \\
SC & $(6.31 \mathrm{e}-05)$ & $(7.59 \mathrm{e}-05)$ & $(1.16 \mathrm{e}-05)$ \\
& 0.905 & 0.979 & 0.779 \\
\hline Log-likelihood & $(0.085)$ & $(0.114)$ & $(0.128)$ \\
$\chi 2$ & -3339.505 & -2045.778 & -1103.515 \\
p-value & 215.32 & 118.72 & 49.65 \\
Obs. & $(0.000)$ & $(0.000)$ & $(0.000)$ \\
\hline & 2838 & 1327 & 1511 \\
\hline
\end{tabular}

Notes. Reported values are hazard ratios. Values below 1 mean a lower hazard rate. Standard errors in parenthesis. ${ }^{* * *}$ Significant at the 0.01 level. **Significant at the 0.05 level. *Significant at the 0.10 level. 
Figure 1. New registrations of digital publishing companies, 1995-2013

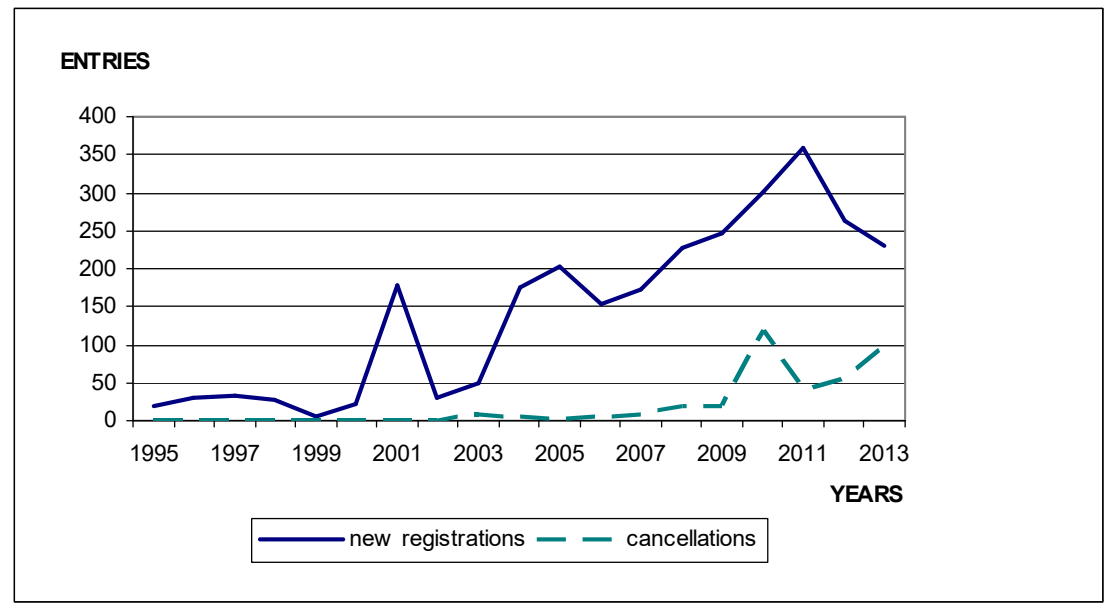

Source: AGCOM.

Figure 2. Share of digital companies operating in print publishing or diversified, 1995-2013.

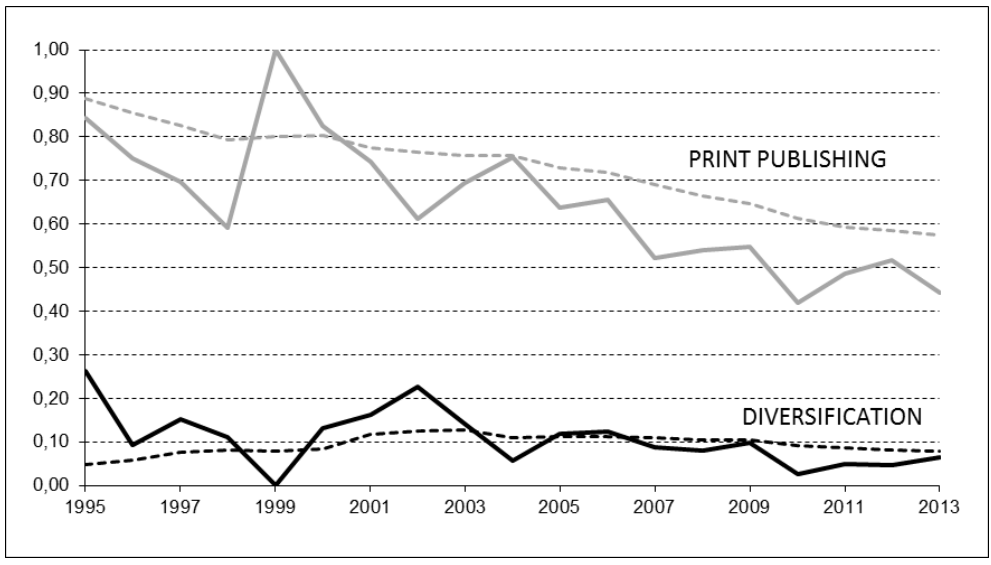

Source: AGCOM. Notes. Solid lines: share of new registrations (considered on a yearly basis) of digital companies operating in print publishing or diversifying. Dotted lines: share of digital companies in print publishing or diversifying. 
Figure 3. Non-parametric survival functions: specialized versus active in print digital publishing companies

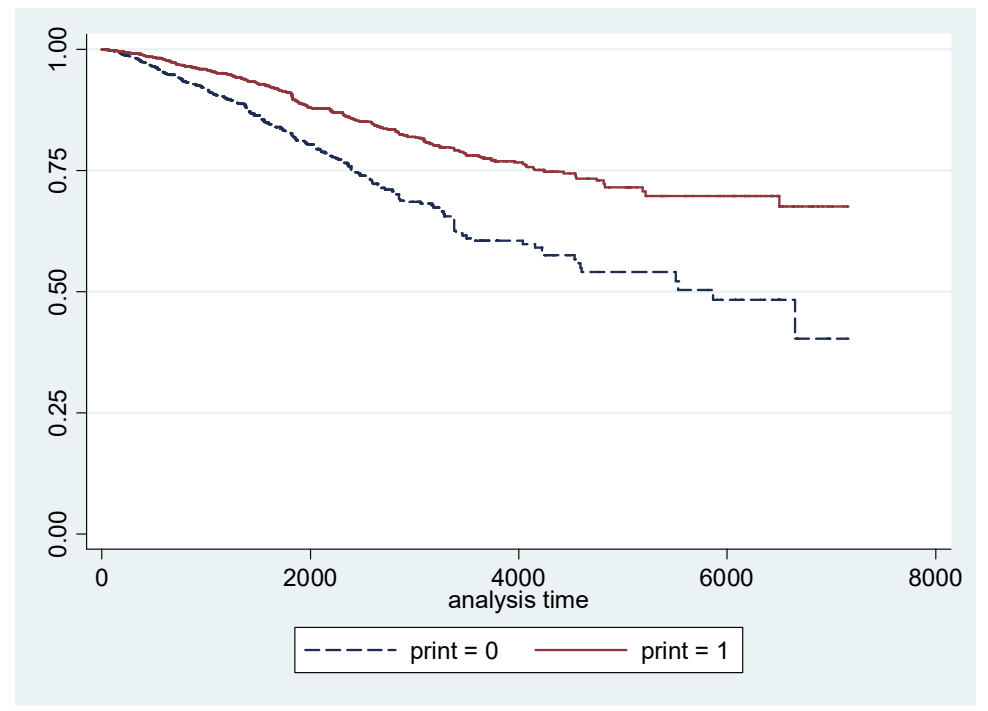

Figure 4. Non-parametric survival functions: specialized versus diversified digital publishing companies

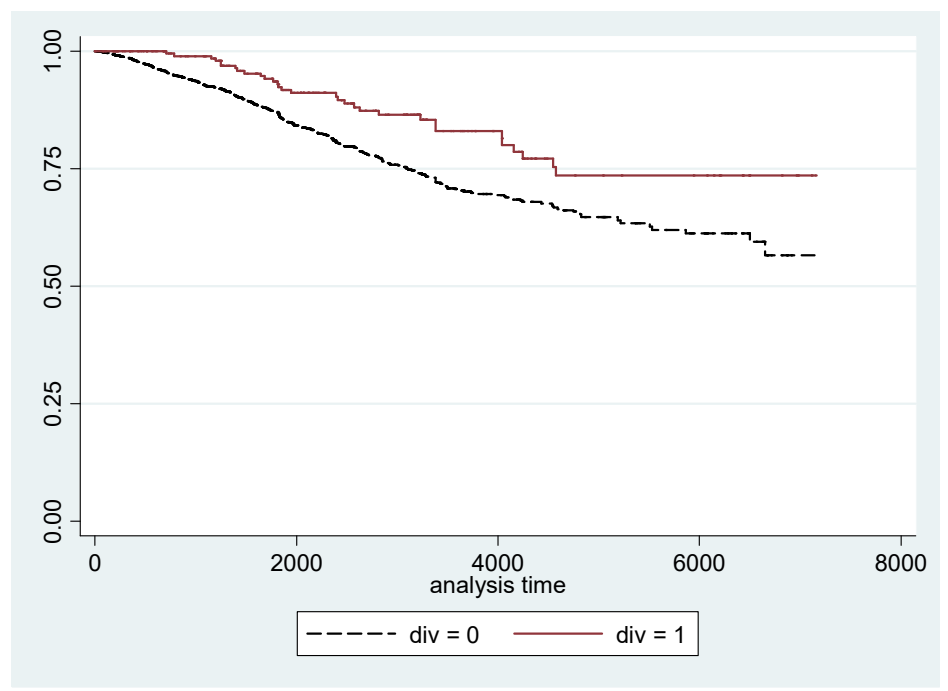


Figure 5. Smoothed hazard function for print and non-print digital publishing companies.

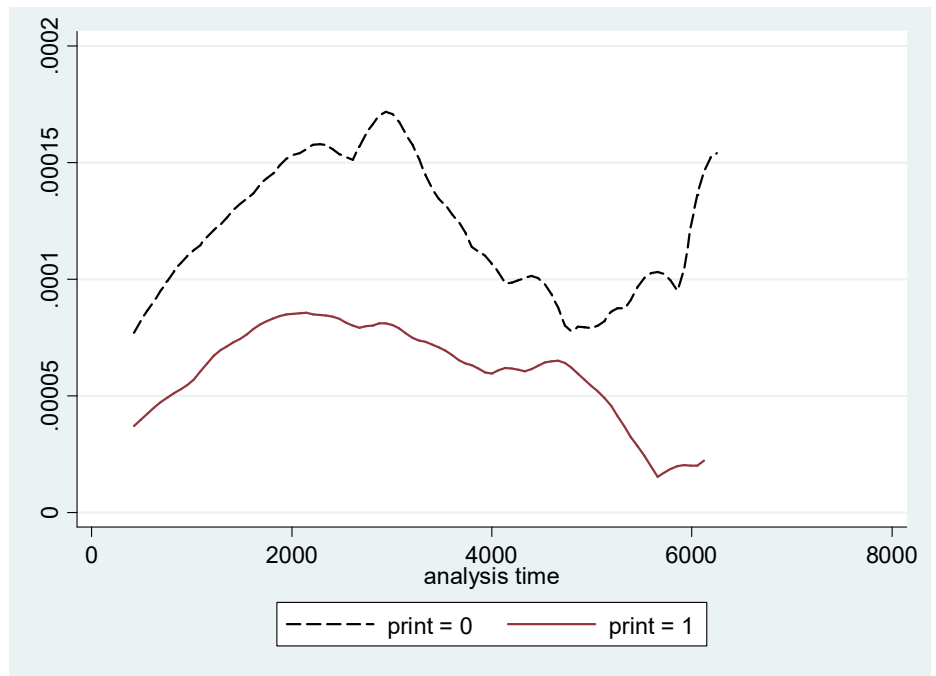

